Não nascemos apenas na posse de nossa liberdade, mas com a incumbência de defendê-la (La Boétie)

\title{
A TEORIA DOS SISTEMAS E A HERMENÊUTICA: PONDERAÇÕES INTRODUTÓRIAS A RESPEITO DO PAPEL DO DIREITO ENQUANTO PRÁXIS SOCIAL EFETIVA
}

\author{
Valéria Ribas do Nascimento ${ }^{1}$
}

\begin{abstract}
RESUMO: A teoria dos sistemas e a hermenêutica apresentam-se como duas correntes doutrinárias complexas, que abordam assuntos polêmicos envolvendo direito, filosofia e sociologia. Dessa maneira, considerando a abrangência do tema, de forma alguma se objetiva esgotar a matéria, mas sim apontar noções introdutórias referentes ao papel do direito enquanto práxis social efetiva e não apenas dogmática. Ademais, com esta exposição procura-se buscar alternativas viáveis, além da simples idéia "melhor ou pior" doutrina, para que o direito adquira uma perspectiva de abertura, relacionada as demais áreas do conhecimento humano. O método de abordagem adotado será o dialético, pois sendo o mundo um conjunto de processos, propugna-se que no caso tome-se a ciência do Direito, que é histórica, a partir de suas contradições internas numa ação recíproca, levando em conta as constantes mudanças em sociedade.
\end{abstract}

PALAVRAS-CHAVE: Direito, sistemas, hermenêutica e práxis social efetiva.

\section{The Theory of Systems and the Hermeneutic: introductory ponderations to the role of Law while social and effective praxis}

\begin{abstract}
The systems theory and the hermeneutics come as two complex doctrinarian currents that approach controversial subjects involving right (the legal system), philosophy and sociology. In that way, considering the wideness of the theme, there is no intent or aim to drain the matter, but to point introductory notions regarding the paper of the right (the legal system) as effective social praxis, not merely dogmatic. Besides, with the presentation tries to look for viable alternatives, above and beyond the simple idea of "better or worse" doctrine, for the right (the legal system) to purchase an opening perspective, related the other areas of the human knowledge. The approach method adopted will be the dialectic, for the reason that, being the world an assemblage of processes is to take the science that is historical starting from your internal contradictions in a reciprocal action, taking into account the constants changes in the society.
\end{abstract}

KEY-WORDS: Right (Legal system), systems, hermeneutics and effective social praxis.

\footnotetext{
${ }^{1}$ Mestre em Direito Público pela Universidade de Santa Cruz do Sul (UNISC); Graduada em Direito pela Universidade Federal de Santa Maria (UFSM); Professora de Direito Constitucional I, II e Processo Constitucional, da Faculdade de Direito de Santa Maria (FADISMA); e-mail:valribas@terra.com.br.
} 


\section{Introdução}

O presente trabalho tem por fim apresentar ponderações introdutórias sobre a teoria dos sistemas e a hermenêutica, bem como demonstrar a contribuição que as mesmas trouxeram para o direito, enquanto ciência relacionada a uma práxis efetiva, que realmente atenda aos interesses humanos que compõe a sociedade.

Assim, foi dividido em dois capítulos. O primeiro trata a respeito da teoria dos sistemas, realizando uma abordagem geral sobre o tema, inserindo, nesse contexto o direito. Posteriormente, faz uma análise - ainda que superficial - das principais teorias neo-sistêmicas: a teoria da diferenciação de Luhmann, que busca através da diferença produzir o sentido de uma decisão e a teoria da ação comunicativa de Habermas, que propõe o consenso para atingir a identidade do sistema.

No segundo capítulo, antes de adentrar na hermenêutica jurídica, relata-se brevemente, noções sobre a hermenêutica filosófica. Ulteriormente, é demonstrada a importância da interpretação na busca do melhor sentido da norma para o ordenamento jurídico. Além disso, no decorrer do texto procura-se realizar uma comparação entre a teoria dos sistemas e a teoria hermenêutica, com objetivo de observar há relação entre elas, no sentido da busca de alternativas para se compreender o sentido do direito.

Dessa maneira, através de uma nova forma de contemplar o Direito objetiva-se inserilo dentro da grande teia de micro-sistemas relacionados e existentes na sociedade contemporânea.

\section{O Direito enquanto sistema}

Na passagem do século XX para o XXI ocorreu a modificação do paradigma mecanicista cartesiano ${ }^{2}$, marcado por uma visão fragmentada, para o sistêmico ${ }^{3}$, no qual a maneira de pensar passou a ser observada através de ligações e relações recíprocas. Neste novo

\footnotetext{
${ }^{2}$ Nos séculos XVI e XVII, a visão de mundo medieval, baseada na filosofia aristotélica e na teologia cristã, sofreu uma transformação radical. A noção de um universo orgânico, vivo e espiritual foi substituída pela noção do mundo como uma máquina, e a máquina do mundo tornou-se a metáfora dominante da era moderna. Essa mudança foi realizada pelas novas descobertas em física, astronomia e matemática, conhecidas como Revolução Científica e associadas aos nomes de Copérnico, Galileu, Descartes, Bacon e Newton. Impende observar que o termo mecanicismo cartesiano vem de René Descartes, pois ele criou o método do pensamento analítico, que consiste em quebrar fenômenos complexos em pedaços a fim de compreender o comportamento do todo a partir de suas partes. O universo material, incluindo os organismos vivos era uma máquina, e poderia, em princípio, ser entendido completamente analisando-o em termos de suas partes menores. In: CAPRA, Fritjof. A teia da vida. Uma nova compreensão científica dos sistemas vivos. São Paulo: Cultrix, p. 34.

3 A raiz da palavra "sistema", deriva do grego synhistanai (colocar junto). Entender as coisas sistematicamente é o mesmo que estabelecer relações entre elas. Ibid, p. 39.
} 
modo de enxergar o mundo, as propriedades essenciais de um organismo, ou sistema vivo, são propriedades do todo, que nenhuma das partes possui, e, embora, se possa discernir partes individuais de qualquer sistema, essas partes não são isoladas. A natureza do todo é sempre diferente da mera soma de suas partes. ${ }^{4}$

Como exemplo, pode-se citar a percepção que as pessoas têm de uma "árvore". Ao desenhá-la, geralmente não se fará a raiz. Entretanto, as raízes de uma árvore são, com freqüência, tão notórias quanto suas partes. Além disso, numa floresta, as raízes de todas as árvores estão interligadas e formam uma densa rede subterrânea na qual não há fronteiras precisas entre uma árvore e outra. ${ }^{5}$

Desse modo, o pensamento sistêmico envolve uma mudança da ciência objetiva para a ciência epistêmica, na qual o método de questionamento torna-se parte integral das teorias científicas.

Na década de 70, grande salto foi dado pelos biólogos chilenos, Maturana e Varela, através da teoria autopoiética. Auto, significa "si mesmo" e se refere à autonomia dos sistemas auto-organizadores, e poiese - que compartilha da mesma raiz grega com a palavra "poesia" quer dizer "criação", "construção". Portanto, autopoiese significa "autocriação". 6

Os autores supracitados buscavam uma resposta para um problema histórico da ciência e da filosofia: o da vida. Assim, através de pesquisas neurofisiológicas, enfatizaram o fechamento operacional. Descobriram que um sistema vivo apresenta no seu circuito interno uma interação compacta de seus elementos constituintes, possibilitando sua auto-organização e a auto-produção. ${ }^{7}$

Todavia, posteriormente Prigogine descreve a estrutura de um sistema vivo como uma estrutura dissipativa dando realce a abertura, ao fluxo de energia e de matéria. Portanto, um sistema vivo é ao mesmo tempo, aberto e fechado, é estruturalmente aberto, mas organizacionalmente fechado. ${ }^{8}$

\footnotetext{
${ }^{4}$ Ibid, p. 40.

${ }^{5}$ Ibid, 49.

${ }^{6}$ MATURANA, Humberto; VARELA, Francisco apud CAPRA, Fritjof. A teia da vida. Uma nova compreensão científica dos sistemas vivos. São Paulo: Cultrix, p. 88.

${ }^{7}$ Ibid, p. 88.

${ }^{8}$ PRIGOGINE, Ilya apud CAPRA, Fritjof. A teia da vida. Uma nova compreensão científica dos sistemas vivos. São Paulo: Cultrix, p. 141.
} 
Nesse contexto, Luhmann ${ }^{9}$ utilizando a teoria sistêmica, inseriu o direito na grande rede dos sistemas sociais. ${ }^{10}$ Para tanto elaborou certas diferenciações para com a autopoiese biológica, no intento de adequar esta teoria à realidade dos fenômenos sociais.

Passa-se, agora, à abordagem da teoria dos sistemas aplicada ao Direito, e, posteriormente da crise na qual se encontra a ciência jurídica.

\subsection{Os fundamentos teórico-sistêmicos do ordenamento jurídico}

Mostra-se necessário esclarecer que o sistema biológico apresenta seu elemento constitutivo e sua base reprodutiva na vida, enquanto que o sistema social tem seu ápice na comunicação. ${ }^{11}$ A partir disso, a sociedade que opera mediante linguagem e comunicação adquire tal complexidade que começa a criar subsistemas parcias: de direito, de economia, de biologia, etc.

A teoria dos sistemas busca a ligação de diferentes áreas do saber, e utilizando a física, a química, a biologia e a cibernética, percebe a sociedade como um sistema estruturado de ações significativamente relacionadas. Ou seja, todos os sistemas estão sempre em permanente contato, até mesmo um sistema provoca interferências em outro sistema produzindo inputs, influências externas a esse sistema. ${ }^{12}$ Ao mesmo tempo tem de, alguma maneira, se realimentar, num feedback, para recuperar ou filtrar essas influências, sendo que a partir de outputs, ocorre a comunicação com outros sistemas. ${ }^{13}$

Impõe-se ressaltar, nessa matriz teórica, as noções de complexidade e contingência, encerrando, respectivamente, a idéia de que sempre há em sociedade mais possibilidades do que é possível realizar e a probabilidade de que os resultados das ações sejam diferentes das

\footnotetext{
${ }^{9}$ A obra de Luhmann pode ser entendida como um esforço em formular uma teoria geral da sociedade, na qual busca-se superar a estreiteza da conexão entre micro e macro, e alcançar uma maior precisão conceitual. A sua obra pode ser dividida em duas fases: a primeira, do início dos anos 60 até meados de 80, é a fase em que formulou uma teoria de sistemas funcional-estrutural, tendo por base a diferenciação entre sistema e ambiente; na segunda, posterior aos anos 80, influenciado pela teoria autopoiética, ele define o sistema social como um sistema autopoiético, fechado e auto-referenciado. Ver: NEVES, Clarissa Eckert Baeta. Niklas Lumann e sua obra. In: NEVES, Clarissa Eckert Baeta; SAMIOS, Eva Machado Barbosa (Org.). Niklas Luhmann: a nova teoria dos sistemas. Porto Alegre: Universitária, 1997, p. 10.

${ }^{10}$ Ibid.

${ }^{11}$ FEDOZZI, Luciano. A nova teoria de sistemas de Nicklas Luhmann: uma leitura introdutória. In: NEVES, Clarissa Eckert Baeta; SAMIOS, Eva Machado Barbosa (Org.). Niklas Luhmann: a nova teoria dos sistemas. Porto Alegre: Universitária, 1997, p. 27.

12 ROCHA, Leonel Severo. O direito na forma da sociedade globalizada. In: Anuário do programa de pósgraduação em direito. Mestrado e Doutorado. São Leopoldo: Unisinos, 2001, p. 124.

13 Ibid.
} 
expectativas. ${ }^{14}$ Luhmann transcende a contigência para abarcar o risco, porque este é uma forma de comunicar sobre o futuro, ou uma formação de vínculos com o amanhã, ligada a uma tomada de decisão. ${ }^{15}$

O Direito é visto como uma estrutura que define os limites da sociedade, sendo indispensável para possibilitar uma estabilização de expectativas nas interações sócias. ${ }^{16}$ Neutraliza a contingência das ações individuais, permitindo que cada ser humano possa esperar, com o mínimo de garantia, a solução de um conflito, através de um processo legítimo. ${ }^{17}$

Ferraz Jr, quanto faz a apresentação da obra, de Luhmann, Legitimação pelo procedimento (primeira fase $)^{18}$, afirma que sendo a função de uma decisão absorver e reduzir insegurança, basta que se contorne a incerteza pela certeza de que uma decisão ocorrerá, para legitimá-la. ${ }^{19}$ Em certo sentido se concebe a legitimação como uma ilusão funcionalmente necessária, pois se baseia na ficção de que existe a possibilidade de uma rebelião, só que esta não é, de fato, realizada. ${ }^{20}$

O Direito se legitima na medida em que os seus procedimentos e legislações encontram um reconhecimento generalizado que traz consigo aceitação e obrigatoriedade, independente da satisfação da decisão isolada.

Ocorre que, atualmente, a sociedade está passando por modificações muito rápidas e o ordenamento jurídico não vem acompanhando essas transformações. Exemplo concreto, é o Novo Código Civil Brasileiro, Lei n. ${ }^{\circ}$ 10.406/02, que entrou em vigor em 2003, resultado de um projeto de lei que chegou a Câmara Federal no ano de 1975. Portanto, já nasceu velho, traduzindo o fracasso da codificação, haja vista que fotografa o tempo passado. ${ }^{21}$

Assim, evidencia-se atualmente o problema da inefetividade do direito, pois a legislação existe em tese, mas não há uma práxis cultural e social de total aplicação e aceitação pela população.

\footnotetext{
${ }^{14}$ NEVES, Clarissa Eckert Baeta. Niklas Lumann..., op. cit. pp. 12-13.

${ }^{15}$ Ibid.

${ }^{16}$ LUHMANN, Nickas. Legitimação pelo procedimento. Brasília: Editora Universidade de Brasília, 1980, p. 210.

${ }^{17}$ Ibid.

${ }^{18}$ Ver nota n. ${ }^{\mathrm{o}} 10$.

${ }^{19}$ Ibid, p. 5.

20 Ibid.

${ }^{21}$ ISERHARD, Antônio Maria. A idéia de sistema jurídico e o novo Código Civil: uma contribuição ao desafio hermenêutico da aplicação do direito . In: Anuário do programa de pós-graduação em direito. Mestrado e Doutorado. São Leopoldo: Unisinos, 2001, p. 6.
} 


\subsection{A crise do Direito e a idéia central da teoria da diferenciação e da ação comunicativa}

É corrente na doutrina jurídica a grande contribuição de Kelsen ${ }^{22}$ para o Direito; todavia, não se pode mais insistir na dogmática jurídica desvinculada das outras áreas do conhecimento humano. Nesse sentido é que foi instituída a Constituição brasileira de 1988, ultrapassando a visão rígida do positivismo jurídico e privatista para dar lugar a uma visão comunitária, ${ }^{23}$ tutelando os direitos fundamentais do ponto de vista social, como valores ou fins que a sociedade se propõe a seguir.

A atual Carta Maior caracteriza-se por ter uma estrutura aberta, pois não há nenhum preceito que impeça tecnicamente que ela admita conteúdos de outros ordenamentos ou de valores da sociedade que a fundamentam e a inspiram, mas que por variadas razões não os acolheu (art. $5^{\circ}$, inc. LXXVII, $\S 2^{\circ}, \mathrm{CF}$ ). Então, percebe-se que a Constituição atual possui cláusulas que possibilitam a análise sistemática pelo Juiz em determinados casos.

Não há como olvidar que o Direito é apenas um dos processos sociais de coexistência, visto que, ao lado dele, existem outros que também contribuem para o provimento eficaz do equilíbrio social. Dentre eles, pode-se elencar os processos morais, os religiosos, etc. ${ }^{24}$

Consoante Iserhard, por não coincidirem o jurídico, o moral e o religioso é que guardam cada um deles uma função específica de coexistência, enquanto processo social. ${ }^{25}$ Refere que, muitas vezes, o processo moral serve para suprir a ausência de regras deixadas pelo jurídico, como pode acontecer o inverso, de o jurídico dar a resposta a problemas morais dos indivíduos. ${ }^{26}$

Com o que foi exposto percebe-se, nitidamente, a relação do Direito com os demais sistemas existentes na sociedade. Dessa forma, vislumbra-se a importância das teorias neosistêmicas, quais sejam a teoria da diferenciação e da ação comunicativa, como possibilidades de solução para a crise do ordenamento jurídico.

\footnotetext{
22 O positivismo jurídico de Hans Kelsen nega qualquer direito além da ordem jurídica posta pelo Estado. Ademais, afirma que uma ordem jurídica positiva é, quanto a sua validade, independente da norma de justiça. In: Teoria pura do direito. São Paulo: Martins Fontes, 1998. p. 427. Ainda, cita-se a obra de COELHO, Fabio Ulhoa. Para entender Kelsen. 4. ed. São Paulo: Saraiva, 2001, p. 74.

23 As características principais do constitucionalismo comunitário são a realização das liberdades positivas (limitação da autonomia individual em prol do coletivo) e dos valores fundamentais elencados na Carta Maior. Para um estudo mais aprofundado, ver: CITTADINO, Gisele. Pluralismo, direito e justiça distributiva. Elementos da filosofia constitucional contemporânea. 2. ed. Rio de Janeiro: Lumen Juris, 2000, p. 246.

${ }^{24}$ ISERHARD, Antônio Maria. O conceito de direito em Pontes de Miranda. Iserhard/ Florianópolis: UFSC, 1994. Tese. (Doutorado em Direito). Curso de Pós-Graduação em Direito, Universidade Federal de Santa Catarina, 1994, p. 176.

25 Ibid.

${ }^{26}$ Ibid.
} 
A teoria da diferenciação proposta por Luhmann e inspirada na dialética, afirma que não é o consenso que produz o sentido da decisão, mas a diferenciação. ${ }^{27}$ Acontece que os sistemas adquirem a sua identidade numa permanente diferenciação com o ambiente e os outros sistemas, graças às decisões das organizações.

Nesse viés, é a atuação do Poder Judiciário quando produz nos processos, os julgamentos do sistema do Direito. Para chegar-se à decisão é necessário haver, anteriormente, a comunicação entre as partes e o Juiz e essa comunicação se articularia como uma síntese entre informação, ato de comunicação e compreensão. ${ }^{28}$

$\mathrm{Na}$ sua concepção autopoiética (segunda fase) ${ }^{29}$, Luhmann radicaliza a sua crítica à sociedade. Aponta que a presença constante e permanente do risco de não se obter consequiências racionais em relação aos fins pretendidos nas decisões, gera o inevitável paradoxo da comunicação para a sociedade, impedindo a diferenciação entre a operação de fechamento e abertura dos sistemas. ${ }^{30}$

O risco coloca a importância da utilização da teoria dos sistemas na tomada de decisão pelo Poder Judiciário, pois através de uma concepção mais ampla é possível observar melhor as conseqüências de certos julgados para a sociedade em geral. Salienta-se que, sempre, observando as particularidades do caso concreto.

Como exemplo, pode-se mencionar o caso de um Juiz que indefere o pedido de despejo por falta de pagamento proposto contra uma senhora idosa, fundamentando sua decisão no direito de moradia para todo cidadão. Essa decisão singular, na verdade, pode acarretar um prejuízo para a maioria das idosas, porque nenhum proprietário vai querer locar, sabendo que poderá não receber o valor dos aluguéis, e alem disso, nem mesmo, ser restituída a posse do seu imóvel. Assim, a teoria da diferenciação acentua a produção da diferença e da fragmentação para através dela se enfrentar o risco e a complexidade da sociedade atual.

Já, na teoria da ação comunicativa ou do agir comunicativo ${ }^{31}$ de Habermas, o sistema adquire a sua identidade a partir do consenso. ${ }^{32}$ Nessa perspectiva, ele propõe a informalização do Direito através do critério "procedural" que se diferencia do formalismo normativista e do

\footnotetext{
27 ROCHA. Leonel Severo. Interpretação jurídica: semiótica: diferenciação e ação comunicativa. In: LEAL, Rogério Gesta; ARAÚJO, Ernani Bonesso (Org.). Direitos sociais e políticas públicas. Desafios contemporâneos. Santa Cruz do Sul: Edunisc, 2001, p. 236.

${ }^{28}$ Ibid, p. 237.

${ }^{29}$ Ver nota n. ${ }^{\circ} 10$.

${ }^{30}$ Ibid, p. 238.

${ }^{31}$ Para uma leitura mais aprofundada a respeito da teoria do "agir comunicativo", ver: HABERMAS, Jürgen. Direito e democracia: entre facticidade e validade. Rio de Janeiro: Tempo Brasileiro, 1997, p. 354.

${ }^{32}$ ROCHA. Leonel Severo. Interpretação Jurídica..., op. cit. p. 239.
} 
modelo hermenêutico material, pelo fato de fundar a sua validade no respeito a procedimentos de elaboração discursiva das normas. ${ }^{33}$

Rocha refere que a possibilidade prática de testar a hipótese de Habermas pode ser feita através da análise de novos fenômenos de informalização e acesso à justiça, como é o caso da resolução de conflitos por meio da arbitragem, negociação e mediação. ${ }^{34}$

O agir comunicativo está relacionado com integração de indivíduos socializados, atuando como participantes no processo. Esse exercício provoca a tensão entre facticidade e validade, embutida na linguagem e no uso da linguagem.

Habermas ao considerar o conceito de razão comunicativa, o situa no âmbito de uma teoria reconstrutiva da sociedade. ${ }^{35}$ Nesse contexto, as formas de comunicação da formação política da vontade do Estado, da legislação e da jurisprudência, aparecem como partes de um processo mais amplo de racionalização dos mundos $d a v i d a^{36}$ de sociedades modernas pressionadas pelos imperativos sistêmicos. ${ }^{37}$

Dessa forma, percebe-se que Luhmann vai inspirar-se na produção da diferença, e Habermas no consenso. Todavia, além dessas duas teorias que apontam como alternativas para a crise do Direito, não há como deixar de mencionar a importância da teria hermenêutica, abordada a seguir.

\section{Considerações sobre a Hermenêutica}

Como já foi mencionado, o ordenamento jurídico caracteriza-se por ser um microsistema que sofre permanentemente a influência dos demais. A título de exemplificação citase: a economia, a política, a religião, etc., que influenciam permanentemente na elaboração e reformulação de suas normas.

Por isso, a necessidade de que os operadores jurídicos ultrapassem a concepção cartesiana - influenciada pela filosofia da consciência - em que há separação sujeito-objeto, marcada pela desviculação da realidade social, para enxergar a importância do resgate de uma práxis cultural que busque ressaltar a importância da linguagem e, portanto, da hermenêutica na aplicação do direito.

\footnotetext{
${ }^{33}$ Ibid.

${ }^{34}$ Ibid.

${ }^{35}$ HABERMAS, Jürgen. Direito e democracia ..., op. cit. p. 22.

${ }^{36}$ Esse termo, utilizado por Habermas na obra referida, significa o ambiente, no qual estão inseridos os sistemas.

37 Ibid.
} 
A filosofia hermenêutica heideggeriana ${ }^{38}$ e a hermenêutica filosófica gadameriana ${ }^{39}$ aplicadas ao Direito, projetam as linhas mestras a respeito do uso da linguagem na constituição do ser dos entes jurídicos e são essenciais para que se instituir uma nova maneira de pensar e entender o sentido do Direito. ${ }^{40}$

Vislumbra-se assim, a importância da hermenêutica não só como forma de interpretação das regras jurídicas, mas também como uma forma de adequá-las as constantes modificações sociais. Pode-se mudar a interpretação de determinada norma, sem modificar o próprio texto, o que levaria muito mais tempo, sem olvidar, de todos os requisitos necessários para promulgação de uma nova lei.

\subsection{O Dasein (ser aí) do Direito: na busca pela efetividade das normas jurídicas}

$\mathrm{O}$ atual momento em que se encontra o Direito necessita de meios para incidir, de forma mais efetiva, na solução dos conflitos. Nesse passo, verifica-se a utilização da hermenêutica, que trabalha com o dar sentido ao texto jurídico, com o $\operatorname{Dasein}^{41}$ (ser aí). Esta nova forma de exegese busca retirar o véu que encobre os operadores jurídicos, objetiva o desvelamento (alétheia $)^{42}$ da aplicação do Direito ao caso em concreto.

Streck procura, através da filosofia de Heidegger, estabelecer a compreensão como totalidade e a linguagem como meio de acesso ao mundo e aos seus objetivos. ${ }^{43}$ Outrossim, afirma que o compreender só é possível se o homem é um ser-no-mundo, nosso acesso ao mundo só é possível pela linguagem. ${ }^{44}$

\footnotetext{
${ }^{38}$ Heidegger utiliza o método fenomenológico, que se orienta pelo binômio velamento/desvelamento para abordar o sentido do ser. In: HEIDEGGER, Martin. Ser e Tempo. 12. ed. Petrópolis: Vozes, 2002, Parte I, p. 325, e Ser e Tempo. 10. ed. Petrópolis: Vozes, 2002, Parte II, p. 262.

${ }^{39}$ Essa hermenêutica trata da linguagem não apenas como objeto, mas horizonte aberto e estruturado. Assim, a hermenêutica é universal. In: GADAMER, Hans Georg. Verdade e método I. Traços Fundamentais de uma hermenêutica filosófica. Petrópolis: Vozes, 2003, p. 631, e Verdade e método II. Complementos e índice. Petrópolis: Vozes, 2003, p. 620.

${ }^{40}$ SALDANHA, Jânia Maria Lopes. A hermenêutica constitucional provocando o (re) pensar do Direito Processual Civil: O vir-à-fala dos seus princípios informativos. Monografia apresentada no IV Congresso Internacional de Direito Processual Constitucional. Área de Concentração: Direito Processual Constitucional. Recife, 2003, pp. 7-8.

${ }^{41}$ O Dasein pode ser traduzido como ser aí ( $D a=$ aí; sein= ser) e como pré-sença. Ver STRECK, Lenio Luiz. Hermenêutica jurídica e $(m)$ crise. Uma exploração hermenêutica da construção do Direito. 2 ed. rev. ampl. Porto Alegre: Livraria do Advogado, 2000, p. 178.

${ }^{42}$ Para Heidegger deve-se traduzir a palavra alétheia por "desvelamento", em lugar de "verdade", pois essa tradução não é somente mais literal, mas ela compreende a indicação de repensar mais originalmente a noção corrente de verdade como conformidade de enunciação, no sentido, ainda incompreendido, do caráter de ser desvelado e do desvelamento do ente. Ibid, p. 187.

${ }^{43}$ Ibid, p. 183.

${ }^{44}$ Ibid.
} 
Dessa forma, o Dasein reside em uma pré-compreensão, e está é que dá o sentido do poder-ser, entrando aí a noção de ser-no-mundo. Essa concepção rompe com qualquer possibilidade de um saber reprodutivo a cerca do Direito, acentuando que a interpretação da lei é uma tarefa criativa. Daí que, os diversos princípios existentes no ordenamento, devem ser aplicados dependendo do caso jurídico concreto, ingressando a fundo na matéria objeto de litígio.

Releva anotar que o Estado Democrático de Direito, instituído com a Constituição de 1988, muito mais do que uma fórmula ou modelo de Estado, é uma proposta civilizatória, é um plus normativo, vinculando a um todo principiológico o agir dos demais entes estatais. ${ }^{45}$

Acontece que a Carta Maior padece de inefetividade. E, suas regras permanecem ocultas do ordenamento jurídico, não ocorrendo a implementação dos direitos individuais e coletivos (com a "desculpa" de serem eles normas programáticas). Vale consignar que a Constituição é importante para a totalidade das normas jurídicas, pois tutela os direitos fundamentais da pessoa humana, abarcando o Direito do Trabalho, Cível, Administrativo, Penal, Processual, etc.

Sendo assim, deve-se buscar através da hermenêutica uma Constituição de resultados, e também, um ordenamento de resultados, preocupado não só com a boa elaboração legislativa, mas também com a aplicação do Direito material e processual.

Passa-se, agora, a verificação da relação entre a teoria dos sistemas e da teoria hermenêutica, como maneira de fortalecimento do micro-sistema jurídico.

\subsection{A mudança de percepção como forma de enriquecimento do Direito}

Consoante afirma Rocha, a hermenêutica jurídica surge quando se percebe a insuficiência das normas jurídicas na solução dos litígios, e pretende através da interpretação social complementá-las. ${ }^{46}$ Entretanto, afirma que existem lacunas teóricas, pois ela não explica razoavelmente a sociedade. ${ }^{47}$

Nessa perspectiva, a teoria dos sistemas seria o melhor caminho para solução das lides. Através de uma visão mais ampla, os operadores jurídicos verificariam o todo, e dentro dele o problema do risco e da complexidade, que está por trás da produção das decisões, pois estas influenciam diretamente na sociedade.

\footnotetext{
45 Ibid.

${ }^{46}$ ROCHA, Leonel Severo. O direito na forma..., op. cit. p. 119.

${ }^{47}$ Ibid, pp. 119-120.
} 
No tocante à teoria hermenêutica, pode-se dizer que ela entende o Direito como transformador. Portanto, Streck, critica as teses sistêmicas autopoiéticas, afirmando que não há como reduzir complexidades, e o procedimentalismo habermasiano que se fundamenta a partir de valores procedimentais adjetivos. ${ }^{48}$

Sucede que tanto a teoria dos sistemas como a teoria hermenêutica são fundamentais para a compreensão das possibilidades que existem no Direito para solucionar litígios. Não há como negar, consoante afirma Capra, a idéia do planeta Terra como um sistema vivo, autoorganizador, composto por uma teia de micro-sistemas interligados e que se influenciam mutuamente, atuando de forma estrutural aberta e organizacional fechada. ${ }^{49}$

O Direito é um desses sistemas que recebe influência não só das ciências sociais, mas também dos próprios sistemas vivos inseridos na comunidade.Por outro lado, a teoria hermenêutica mostra a possibilidade de des-velamento das normas jurídicas através do Dasein (ser- aí), ou seja da busca pela melhor aplicação da norma para determinado caso concreto.

Assim, é claro que existem diferenças substanciais entre as duas teorias. Porém, através de uma mudança de percepção, vislumbra-se a possibilidade dessas correntes se desenvolverem paralelamente, e de forma coerente procurarem alternativas viáveis para a efetividade do ordenamento jurídico.

\section{Considerações Finais}

A ciência do Direito do século atual em compasso com tantos outros ramos do conhecimento humano sofre transformações. Dentro dessas modificações estão inseridas a teoria sistêmica e a hermenêutica.

A primeira percebe a conexão que há entre diferentes núcleos existentes em sociedade. Dessa maneira, extrai-se a concepção de autopoiese: sistema simultaneamente fechado e aberto que busca a formação da diferença, equacionando as idéias de complexidade e risco para aplicação do Direito, realçando as conseqüências que poderão ocorrer para coletividade.

Já, a teoria hermenêutica busca o ser-aí, ou em outras palavras, o dar sentido ao texto jurídico, caracterizado pela interpretação da norma no caso concreto. Nesse sentido, a

\footnotetext{
${ }^{48}$ STRECK, Lenio Luiz. A hermenêutica, a lei e a justiça: a discussão dos obstáculos ao acontecer da Constituição. In: LEAL, Rogério Gesta; ARAÚJO, Ernani Bonesso (Org.). Direitos sociais e políticas públicas. Desafios contemporâneos. Santa Cruz do Sul: Edunisc, 2001, p. 118.

${ }^{49}$ CAPRA, Fritjof. A teia da vida..., op. cit. p. 256.
} 
hermenêutica procura analisar o direito e o fato em uma relação de coexistência e interdependência, para assim atingir-se a verdade e a justiça social.

Tanto a teoria sistêmica como a hermenêutica, apresentam alternativas viáveis, mas diferenciadas, para a questão do real sentido do direito. Todavia, é importante observar que a discussão não deve girar em torno "da melhor ou pior" doutrina, mas sim na busca de novas opções que visem aperfeiçoar o ordenamento jurídico.

À guisa de conclusão, insta ressaltar a inegável dificuldade em dar respostas sobre a aplicabilidade do Direito. Por isso, a importância de estudos epistemológicos sobre o assunto. Talvez Fernando Pessoa estivesse certo quando disse: Falhados pensamentos e sistemas, que, por falharem, só mais negro fazem o poder horroroso que os transcende (...).

\section{Referências Bibliográficas}

CANARIS, Claus Wilhelm. Pensamento sistemático e conceito de sistema na ciência do direito. 3. ed. Lisboa: Fundação Calouste Gulbenkian, 2002, p. 311.

CAPRA, Fritjof. A teia da vida. Uma nova compreensão científica dos sistemas vivos. São Paulo: Cultrix, 1999, p. 256.

CITTADINO, Gisele. Pluralismo, direito e justiça distributiva. Elementos da filosofia constitucional contemporânea. 2. ed. Rio de Janeiro: Lumen Juris, 2000, p. 246.

COELHO, Fábio Ulhoa. Para entender Kelsen. 4.ed. São Paulo: Saraiva, 2001, p. 74.

FEDOZZI, Luciano. A nova teoria de sistemas de Nickas Luhmann: uma leitura introdutória. In: NEVES, Clarissa Eckert Baeta; SAMIOS, Eva Machado Barbosa (Org). Nicklas Luhmann: a nova teoria dos sistemas. Porto Alegre: Universitária, 1997, pp. 18-33.

GADAMER, Hans Georg. Verdade e método I.Traços Fundamentais de uma hermenêutica filosófica. Petrópolis: Vozes, 2003, p. 631.

Verdade e método II.Complementos e índice. Petrópolis: Vozes, 2003, p. 620.

HABERMAS, Jürgen. Direito e democracia: entre facticidade e validade. Rio de Janeiro: Tempo Brasileiro, 1997, p. 354.

HEIDEGGER, Martin. Ser e Tempo. 12. ed. Petrópolis: Vozes, 2002, Parte I, p. 325. 
. Ser e Tempo. 10. ed. Petrópolis: Vozes, 2002, Parte II, p. 262.

HELFER, Inácio; AGNES, Clarice. (Org.). Normas para apresentação de trabalhos acadêmicos. 5. ed. rev. e ampl. Santa Cruz do Sul: Edunisc, 2001, p. 60.

ISERHARD, Antônio Maria. A idéia de sistema jurídico e o novo Código Civil: uma contribuição ao desafio hermenêutico da aplicação do direito. In: Anuário do programa de pós-graduação em direito. Mestrado e Doutorado. São Leopoldo: Unisinos, 2001, pp. 1-16.

O conceito de direito em Pontes de Miranda. Iserhard/Florianópolis: UFSC, 1994. Tese. (Doutorado em Direito). Curso de Pós-graduação em Direito, Universidade Federal de Santa Catarina, 1994, p. 176.

KELSEN, Hans. Teoria pura do direito. São Paulo: Martins Fontes, 1998. p. 427.

LUHMANN, Nicklas. Legitimação pelo procedimento. Brasília: Editora Universidade de Brasília, 1980, p. 210.

NEVES, Clarissa Eckert Baeta. Nicklas Luhmann e sua obra. In: NEVES, Clarissa Eckert Baeta; SAMIOS, Eva Machado Barbosa (Org). Nicklas Luhmann: a nova teoria dos sistemas. Porto Alegre: Universitária, 1997, pp. 9-17.

NICOLA, Daniela Ribeiro Mendes. Estrutura e função do direito na teoria da sociedade. In: ROCHA, Leonel Severo Rocha (Org). Paradoxos da auto-observação: percursos da teoria jurídica contemporânea. Curitiba: JM Editora, 1997, pp. 221-242.

ROCHA, Leonel Severo. Interpretação jurídica: semiótica, diferenciação e ação comunicativa. In: LEAL, Rogério Gesta; ARAÚJO, Ernani Bonesso (Org). Direitos sociais e políticas públicas. Desafios contemporâneos. Santa Cruz do Sul: Edunisc, 2001, p. 227-242.

O direito na forma da sociedade globalizada. In: Anuário do programa de pósgraduação em direito. Mestrado e Doutorado. São Leopoldo: Unisinos, 2001, pp. 117-137.

SALDANHA, Jânia Maria Lopes. A hermenêutica constitucional provocando o (re)pensar do Direito Processual Civil: O vir-à-fala dos seus princípios informativos. Monografia apresentada no IV Congresso Internacional de Direito Processual Constitucional. Área de Concentração: Direito Processual Constitucional. Recife, 2003, pp. 1-27.

STRECK, Lenio Luiz. A hermenêutica, a lei e a justiça: a discussão dos obstáculos ao acontecer da Constituição. In: LEAL, Rogério Gesta; ARAÚJO, Ernani Bonesso (Org.). 
Direitos sociais e políticas públicas. Desafios contemporâneos. Santa Cruz do Sul: Edunisc, 2001, pp. 111-157.

Hermenêutica jurídica $\mathbf{e}(\mathbf{m})$ crise: uma exploração hermenêutica da construção do Direito. 2. ed. rev. ampl. Porto Alegre: Livraria do Advogado, 2000, p. 304. 